\title{
Testing the Efficiency of the Art Market using Quantile-Based Unit Root Tests with Sharp and Smooth Breaks ${ }^{\#}$
}

\author{
Goodness C. Aye*, Tsangyao Chang*, Wen-Yi Chen`, Rangan Gupta` and Mark E. Wohar`
}

\begin{abstract}
This paper examines the efficiency market hypothesis for the art market using a novel nonlinear quantile-based unit root test while accounting for sharp shifts and smooth breaks in the data. We use quarterly data which covers 1998:1 and 2015:1. Our analysis is based on 15 art price indices: Contemporary, Drawings, France, Global index (Euro), Global index (USD), Modern art, Nineteenth century, Old Masters, Paintings, Photographies, Postwar, Prints, Sculptures, UK and US. We find evidence of structural shifts and nonlinearity in the art indices. We cannot reject the null of unit root and/or stationarity in the art series based on the conventional linear unit root tests and quantile-based test that did not account for structural breaks. However, when we use the same methods but accounting for sharp shifts and smooth breaks, we are able to reject the unit root null for each of the art indices. Further we find evidence of asymmetric behaviour in some of the indices: two global indices, Paintings, Prints, Sculptures, Modern art and Postwar, where unit root exist at some quantiles but not at others. Overall, our result suggest that the art market is inefficient. We provide some practical and policy implications of our findings.
\end{abstract}

JEL Codes: C22, G10, G23

Keywords: Art market; efficiency, sharp and smooth breaks; conventional unit root tests; quantile unit root tests

\footnotetext{
\# We would like to thank an anonymous referee for many helpful comments. However, any remaining errors are solely ours.

* Department of Economics, University of Pretoria, Pretoria, 0002, South Africa. Email: goodness.aye@gmail.com.

* School of Finance, Hubei University of Economics, Hubei, China. Email: tychang@fcu.edu.tw.

- Department of Senior Citizen Service Management, National Taichung University of Science and Technology, Taichung, Taiwan. Email: chenwen@,nutc.edu.tw.

^Department of Economics, University of Pretoria, Pretoria, 0002, South Africa. Email: rangan.gupta@up.ac.za.

- Corresponding author. College of Business Administration, University of Nebraska at Omaha, 6708 Pine Street, Omaha, NE 68182, USA, and School of Business and Economics, Loughborough University, Leicestershire, LE11 3TU, UK. Email: mwohar@unomaha.edu.
} 


\section{Introduction}

Every investor seeks the highest possible return from his or her investment conditional on the level of risk. However, portfolios are not always guaranteed to yield the highest expected returns. When faced with under-performing portfolios, investors would look for alternative assets to acquire high returns while minimizing risk. Despite some peculiar features possessed by art and its markets, such as heterogeneity and illiquidity, artworks are seen as both consumable goods and financial assets by early scholars and economists (Stein, 1977; Baumol 1986). The market for art has existed for over five centuries when collectors, in the 16th century, started acquiring works of art for esthetic reasons, social status, and as a means of investment. Despite this long period of existence, the art market somehow remained opaque (Kräussl et al., 2016).

There is currently a growing interest in the art market from both academics and practitioners. One of the major questions relates to the returns on investing in art assets. There are divergent views and/or empirical findings regarding this. For instance, in analyzing the historical financial gains from artworks, Campbell (2008) shows that although arts provide a small addition to investors' investment strategy, they are attractive and offer diversification benefits as investment portfolio since they showed low correlation with other asset classes. McAndrew (2008) estimates the global art market (auction and private deals) to be over $\$ 3$ trillion with a $\$ 50$ billion annual turnover while Artprice (2013) shows that as of 2012, the auction market for art represents a total of $\$ 12.3$ billion worldwide. According to the Art and Finance Report 2014, depending on the region, wealthy investors allocate 6 to $18 \%$ of their total wealth to art and collectibles and the majority of wealth managers and family offices strongly believe that there is a role for art in balanced portfolio and asset diversification strategy (Picinati di Torcello and Petterson, 2014).

Art indices are also considered good investment options or strategies because for a very long time the average annual returns remained as high as 10\% (Munteanu and Pece, 2015). Further, Renneboog and Spaenjers (2013) show that between 1982 and 2007, art prices (hedonic 
price index of drawings, oil paintings and watercolors) increased annually by $3.97 \%$ with returns from physical and financial assets trailing behind this figure: commodities $(3.3 \%)$, gold $(2.35 \%)$, T-Bills $(1.39 \%)$ and US real estate (1.06\%). Contrary to the optimistic view about art investment, Korteweg et al. (2015) argue that the returns and risks involved in the selling and buying of art works are respectively overestimated and underestimated by investors. In an empirical analysis using a sample of 32,928 paintings that sold repeatedly between 1960 and 2013, Korteweg et al. (2015) show that average annual return from art investment fell from $10 \%$ to $6.2 \%$ with other assets outperforming arts: commodities (10.21\%), corporate bonds (8.94\%) and stock (10.95\%).

The ability of an investor to achieve normal or above average (excess) returns from the art market consistently over time will depend to a great extent on the efficiency of the market. Testing for art market efficiency is tightly linked to the predictability of the returns. Many time series variables exhibit trend behaviour and they are relevant to the study of market efficiency. Fama (1970) distinguished between three forms of Efficient Market Hypothesis (EMH): weak form, semi-strong form and strong form efficiency. Weak form efficiency asserts that the current price (return) is unrelated to past price (return). In the semi-strong form, prices reflect all publicly available information while for the strong form efficiency, prices reflect all available information, both public and private (insider). Informational efficiency according to Cochrane (2013) is "a natural consequence of competition, relatively free entry, and low costs of information. If there is a signal, not incorporated in market prices, that future values will be high, competitive traders will buy on that signal. In doing so, they bid the price up, until it fully reflects the information in the signal". In general, in an efficient market, since asset prices fully reflect all available information in the market, no investor can earn excess return on the basis of public or historic information or monopolistic access to private information. In such markets, investors will face near-zero transactions, search, and information costs, and they will share homogeneous expectations about the meaning of newly arrived information (Louargand and McDaniel, 1991). 
Thus, in an efficient market, it is difficult for investors to predict future price movements since the anticipated events are already integrated in the current price.

Market efficiency is key for investors as it gives them confidence in fairness of market valuation. It is also useful for portfolio diversification and risk management. According to Louargand and McDaniel (1991) and Ashenfelter and Graddy (2003), some developments in the art market may support its efficiency namely increase in liquidity due to dramatic growth in art auction turnovers, better information in art auction catalogues, especially due to online resources, globalization, access to financing options, decreasing transaction costs, and the increase of participation in the auction markets among others thus suggesting that art prices should be unpredictable or random (Louargand and McDaniel 1991). This argument has however been countered by some researchers. For instance, David et al. (2013) argued that it is structurally impossible for auction prices to be efficient. This is because sellers set a minimum transaction price on the artworks for which they have a monopoly and hammer prices are determined solely by bidding, so that there is no upper limit. Consequently, relying on realized prices is insufficient to build unbiased predictions of future prices. As will be seen in the literature review section, the conclusions from empirical studies are also mixed. The inconclusive nature of these results therefore warrants more investigation of the art market efficiency.

While most studies have used the standard linear models or unit root tests methods (Louargand and McDaniel, 1991; Chanel, 1995; Hodgson and Vorkink 2004; Worthington and Higgs, 2003) and variance ratio tests (Erdös and Ormos; 2010; David et al. 2013; Munteanu and Pece, 2015; Aye et al., 2016), few have used nonlinear linear tests (Çevik et al., 2013; to examine the art market efficiency. Aye et al.,2016). In this paper, we contribute by examining the efficiency of the art market using a nonlinear unit root test. This is in realization of the fact the behaviour of most economic and financial variables might arise from nonlinear processes. Unlike Çevik et al. (2013) and Aye et al. (2016) whose methods are also nonlinear, we use quantile-based unit root test, a novel method that has not been previously used in the art efficiency literature. 
This method allows us to not only analyze the persistence of art prices and hence market efficiency at the conditional mean or any other single measure of conditional central tendency, but also at the various tails of the distribution. It also allows us to examine possible asymmetry in the behaviour of the art indices, thus providing important insights on the dynamics and persistency in the art indices (Tsong and Lee, 2011). Moreover, the method allows us to account for potential sharp shifts and smooth breaks in the art series. The persistence parameter of a process may be overestimated if structural breaks are omitted or ignored from the unit root tests, consequently decreasing the power to reject a unit root when the stationarity alternative is true (Perron, 1989). Further, evidence has also shown that the quantile unit root rest has more power than standard linear unit root tests (Koenker and Xiao, 2004).

The remainder of the paper is organized as follows: Literature review is presented in section 2. Section 3 discusses the data and the methodology. In section 4 we present and discuss the results, and section 5 concludes.

\section{Literature Review}

Despite the earlier held view that it is impossible to test market efficiency in the context of the art market due to data limitations (Frey and Eichenberger, 1995) arising from infrequent sales and illiquid nature of the art market (Pesando, 1993), with data becoming more available, a number of studies have been conducted in recent times. For instance, Louargand and McDaniel (1991) hypothesize that in an efficient market for art, the expected prices will be equal to the actual prices on average. They test for pricing efficiency using prices from 1,853 transactions in 13 categories of Americana which were sold at auction in five sales during 1989 and 1990 at Sotheby's New York sales rooms. Results based on Martingale model and two-sampled t-tests suggest that auction house experts establish estimated selling price ranges very efficiently in the Martingale sense. The experts' predictions of selling price in eleven of thirteen categories of Americana were not significantly different from the actual selling prices. 
Pesando (1993) investigates the prints market using semi-annual price index over the 1977-1992 period and finds mixed evidence for market efficiency with excess returns being autocorrelated positively for the one-year lag and negatively for the two-year lag. Goetzmann (1995) calculates decade-by-decade returns on painting investments over the period 1720 - 1986. Using serial dependence in returns as a measure of informational efficiency, he finds weak evidence of persistence of trends in the painting market indicating market inefficiency. However, results based on price risk as an alternative measure shows that the price risk has been declining since the beginning of the painting market, indicating increasing informational efficiency.

Chanel (1995) examines the predictability of the art market by analysing the relationship between art market indices and stock market. Prices of the art market were constructed using hedonic regression giving rise to quarterly art market index, covering 1961:4 to 1992:4, containing 25.300 transactions of paintings of 82 well-known artists. The stationarity of the series using unit root tests indicate that each series is first-order integrated. Chanel (1995) noted that accepting the random walk hypothesis is a sign of weak efficiency of the markets.

Worthington and Higgs (2003) examine the short and long-term price linkages among major art and equity markets over the period 1976-2001. The art markets examined are Contemporary Masters, French Impressionists, Modern European, 19th Century European, Old Masters, Surrealists, 20th Century English and Modern US paintings. Results from a number of econometric methods indicate that there is a stationary long-run relationship and significant short and long run causal linkages between the various painting markets and between the equity market and painting markets. They conclude that there may be no gains from pairwise portfolio diversification between those markets where a significant causal relationship exists. Also, they noted that finding of causality in some markets must be seen as violating weak-form efficiency since one of the markets can help forecast the other.

Hodgson and Vorkink (2004) examine the extent to which standard asset pricing theory, as incorporated in the capital asset pricing model (CAPM), can account for price movements in 
the market for Canadian paintings. Annual and semi-annual art price indices were constructed from hedonic regressions using data for auctions held between 1968 and 2001. Results based on Gibbons, Ross, and Shanken (1989) test for market efficiency show that the notion that the art index return behaviour is described by an unconditional CAPM cannot be rejected. This implies that the null hypothesis that the Canadian paintings are ex ante mean-variance efficient cannot be rejected.

Erdös and Ormos (2010) employ variance ratio tests to detect the size of the random walk component of the US art auction prices (combination of the Mei Moses Fine Art Index and the US subindex of the Artprice Global Index family) using annual data from 1875 to 2008. They find that the past 134 years of US art prices exhibit large transitory component $(72 \%)$ and consequently, the random walk hypothesis does not hold. Using a sub-sample analysis to account for detected structural breaks, they find that the random walk hypothesis and the weak-form efficiency of US art market cannot be rejected at least for the past 64 years.

David et al. (2013) propose tests for weak efficiency of the art market using the hedonic art index developed by Renneboog and Spaenjers (2013) and annual data from 1957-2007. Results based on Ljung-Box test show that art returns exhibit highly auto-regressive dynamics. Also the variance ratio tests rejects random walk hypothesis while the run and Bartels tests reject return independence. These findings imply that weak efficiency is rejected for the examined art market.

Using quarterly data from 1990-2011 and Markov regime-switching ADF model, Çevik et al. (2013) show that the overall global art market (in USD) is a stationary process at $1 \%$ level. The price indices for the Sculptures, Photographs, Old Masters, Contemporary, Paintings and Prints are stationary, hence providing evidence of mean-reversion. The price indices for Drawings and Nineteenth century were found to be non-stationary and hence the authors conclude these two exhibit at least weak-form efficiency in some sense. 
Munteanu and Pece (2015) test the market efficiency of the most influential auction house as a signal for art market robustness using daily data from April 2005-March 2014. They focus on how investors use information regarding the activity of four major auction houses Sotheby's, Turners Auctions Ltd, Mallett PLC and Mowbray Collectables - and how this information is reflected in the price of the art indices. Results based on Automatic Variance Ratio test, Joint Wright test, and the Lo and MacKinlay test indicate that while some indices exhibit market efficiency, others present a slow assimilation of information and hence past information can be used to make predictions.

Aye et al. (2016) use both variance ratio tests, linear and nonlinear fractional integration models to examine the efficiency of the art market using quarterly data on 15 art price indices covering the period from 1998 to 2015. They find mixed results depending on the method used. However, US and Contemporary art markets appear to be efficient irrespective of the method used.

\section{Data and Empirical Models}

We use quarterly data on 15 art market price indices. These include Contemporary, Drawings, France, Global index (Euro), Global index (USD), Modern art, Nineteenth century, Old Masters, Paintings, Photographies, Postwar, Prints, Sculptures, UK and US art indices. Our sample covers the period 1998:1 to 2015:1. ${ }^{1}$ The data is sourced from ARTPRICE, available for download from: http://www.artprice.com. The art market price indices are calculated from a repeat-sales model drawn from a database of over 27 million auction records from over 3,600 auction houses around the world. A repeat sales takes place if two works of art are sold sequentially which are by the same artist and their size, technique, materials, medium and the date of creation are matched (Erdös and Ormos, 2010). We prefer to use this data base given the

\footnotetext{
${ }^{1}$ While Çevik et al. (2013) and Atukeren and Seçkin (2009) used Artprice data starting from 1990, our data set starts from 1998. The information we received from Artprice via email communication is that the Department of Econometrics has decided not to calculate indexes prior to 1998 anymore, since the coverage of the global art market only becomes efficient by this date on.
} 
availability of comprehensive dataset and at quarterly frequency. This would allow us to make a more reliable inference about the underlying market efficiency and capture the inherent seasonality present in art auction sales unlike most previous studies that relied on annual, semiannual and even decade-by-decade price indices. All indices are transformed to their natural logarithms. We present the summary statistics of the $\log$ of the art indices in Table 1 . The variation in the data is in general less than 0.5 . While some of the variables are negatively skewed, others are positively skewed and the kurtosis is in general less than 3. However, using a formal test of normality (Jarque-Bera statistic), we conclude that all the series are normally distributed with exception of Contemporary, Drawings, Global index (USD), Photographies and Post war. 
Table 1: Descriptive Statistics of the log of art indices

\begin{tabular}{|c|c|c|c|c|c|c|c|c|c|}
\hline & \multirow[b]{2}{*}{ Mean } & \multirow[b]{2}{*}{ Median } & \multicolumn{4}{|c|}{ Std. } & \multicolumn{3}{|c|}{ Jarque- } \\
\hline & & & Max & Min & Dev. & Skewness & Kurtosis & Bera & Prob \\
\hline Contemporary & 5.091 & 5.219 & 5.651 & 4.573 & 0.324 & -0.284 & 1.656 & $6.117^{* *}$ & 0.047 \\
\hline Drawings & 5.175 & 5.151 & 5.854 & 4.605 & 0.372 & 0.380 & 2.007 & 4.497 & 0.106 \\
\hline France (Euro) & 4.831 & 4.834 & 5.063 & 4.605 & 0.100 & 0.087 & 3.125 & 0.131 & 0.937 \\
\hline Global index (Euro) & 4.975 & 4.973 & 5.255 & 4.605 & 0.152 & -0.432 & 2.916 & 2.167 & 0.338 \\
\hline Global index (USD) & 5.046 & 5.110 & 5.506 & 4.605 & 0.263 & -0.264 & 1.694 & $5.711^{*}$ & 0.058 \\
\hline Modern art & 4.898 & 4.903 & 5.336 & 4.603 & 0.202 & 0.188 & 2.133 & 2.568 & 0.277 \\
\hline Nineteenth century & 4.778 & 4.759 & 5.135 & 4.460 & 0.160 & 0.378 & 2.432 & 2.571 & 0.276 \\
\hline Old Masters & 4.740 & 4.762 & 5.047 & 4.452 & 0.145 & -0.212 & 2.069 & 3.007 & 0.222 \\
\hline Paintings & 4.970 & 5.003 & 5.431 & 4.605 & 0.229 & -0.057 & 2.018 & 2.812 & 0.245 \\
\hline Photographies & 4.972 & 5.030 & 5.403 & 4.454 & 0.241 & -0.575 & 2.501 & $4.521 *$ & 0.104 \\
\hline Post war & 5.224 & 5.398 & 5.807 & 4.593 & 0.378 & -0.432 & 1.733 & $6.767^{* *}$ & 0.034 \\
\hline Prints & 4.879 & 4.940 & 5.296 & 4.561 & 0.192 & -0.093 & 2.177 & 2.049 & 0.359 \\
\hline Sculptures & 4.906 & 4.944 & 5.294 & 4.576 & 0.203 & 0.042 & 1.980 & 3.010 & 0.222 \\
\hline UK (in GBP) & 5.098 & 5.108 & 5.394 & 4.605 & 0.188 & -0.480 & 2.602 & 3.105 & 0.212 \\
\hline US (USD) & 4.996 & 5.067 & 5.365 & 4.605 & 0.193 & -0.260 & 2.280 & 2.265 & 0.322 \\
\hline
\end{tabular}

Note: ${ }^{*}$ and ${ }^{* *}$ indicate rejection at $10 \%$ and $5 \%$ level, respectively.

We use quantile-based unit root test and take into account both sharp shifts and smooth breaks. Let $y_{t}$ denote the $\log$ of art price in our case and $\varepsilon_{t}$ a serially uncorrelated error term. An $\operatorname{AR}(\mathrm{q})$ process for $\log$ art price with $\operatorname{drift} a$ and deterministic trend $t$ is given by:

$$
y_{t}=a+b t+\sum_{i=1}^{q} \gamma_{i} y_{t-1}+\varepsilon_{t}, \quad t=q+1, q+2, \ldots, n
$$

The sum of the autoregressive coefficients is $\alpha=\sum_{i=1}^{q} \gamma_{i}$ - a measure of persistence that we will focus on in our study. We can rewrite Equation (1) as follows:

$$
y_{t}=\alpha y_{t-1}+a+b t+\sum_{i=1}^{q-1} \phi_{i} \Delta y_{t-i}+\varepsilon_{t}
$$


Here we can run the usual unit root test. If $\alpha=1$ then art price has a unit root and, therefore, shocks have permanent effects on art price. If we have $\alpha<1$, then art price is stationary. In this case shocks have only temporary effects on art price.

To model the mean reversion properties in art price with both sharp shifts and smooth breaks for estimation of a level and trend equation. Following Bahmani-Oskoee et al., (2015), we can then specify its function as follows:

$$
y_{t}=\alpha+\beta t+\sum_{l=1}^{m+1} \theta_{l} D U_{l, t}+\sum_{l=1}^{m+1} \rho_{l} D T_{l, t}+\sum_{k=1}^{n} \gamma_{1, k} \sin \left(\frac{2 \pi k t}{T}\right)+\sum_{k=1}^{n} \gamma_{2, k} \cos \left(\frac{2 \pi k t}{T}\right)+\varepsilon_{t}
$$

In equation (3), $\mathrm{t}, \mathrm{T}$, and $\mathrm{m}$ are time trend, sample size and the optimum number of breaks, respectively. The other regressors are defined as the following:

$$
\begin{aligned}
& D U_{k, t}= \begin{cases}1 & \text { if } \quad T B_{k-1}<t<T B_{k} \\
0 & \text { otherwise }\end{cases} \\
& D T_{k, t}= \begin{cases}t-T B_{k-1} & \text { if } \quad T B_{k-1}<t<T B_{k} \\
0 & \text { otherwise }\end{cases}
\end{aligned}
$$

Terms $D U$ and $D T$ are entered in the model to capture the sharp shifts. ${ }^{2}$ Following the work of Gallant (1981), in order to obtain a global approximation from the smooth transition, we use the Fourier approximation and enter both terms of $\sum_{k=1}^{n} \gamma_{1 k} \sin \left(\frac{2 \pi k t}{T}\right)$ and $\sum_{k=1}^{n} \gamma_{2 k} \cos \left(\frac{2 \pi k t}{T}\right)$ into the model. Where $\mathrm{n}$ and $\mathrm{k}$ present the number of frequencies that contained in the approximation and equal to $\mathrm{n} \leq \frac{\mathrm{T}}{2}$ and particular frequency, respectively.

Estimation of equation (3) involves with three issues, the choice of $\mathrm{m}$, the choice of $\mathrm{n}$, and the choice of $\mathrm{k}$. As noted by Becker et.al (2004), it is reasonable that we restrict $\mathrm{n}=1$ because if $\gamma_{1, \mathrm{k}}=\gamma_{2, \mathrm{k}}=0$ can be rejected for one frequency, then the null hypothesis of time invariance is also rejected. Also Enders and Lee (2012) noted that imposing the restriction $n=1$ is useful in

\footnotetext{
2 Equation (3) is not only an extension of Enders and Holt (2012) but also a combination of Carrion-i-Silvestre et al. (2006) and Becker et al. (2006) tests.
} 
order to save the degrees of freedom and prevent from over-fitting problem. Hence we respecify the equation (3) as follows:

$$
y_{t}=\alpha+\beta t+\sum_{l=1}^{m+1} \theta_{l} D U_{l, t}+\sum_{i=1}^{m+1} \rho_{i} D T_{i, t}+\gamma_{1} \sin \left(\frac{2 \pi k t}{T}\right)+\gamma_{2} \cos \left(\frac{2 \pi k t}{T}\right)+\varepsilon_{t}
$$

It is important to note that we can remove the impact of possible structural breaks on art price after the information of break dates. We follow the procedure adopted by Tsong and Lee (2011) and Chen et al., (2015) to reconstruct time series of art price taking into account both sharp shifts and smooth breaks as follows:

$$
y_{t}=a r t_{t}-\hat{\alpha}-\hat{\beta} t-\sum_{l=1}^{m+1} \hat{\theta}_{l} D U_{l, t}-\sum_{i=1}^{m+1} \hat{\rho}_{i} D T_{i, t}-\hat{\gamma}_{1} \sin \left(\frac{2 \pi k t}{T}\right)-\hat{\gamma}_{2} \cos \left(\frac{2 \pi k t}{T}\right)+\varepsilon_{t}
$$

where $y_{t}$ is art price adjusted by the effect of possible structural breaks (for both sharp shifts and smooth breaks), $a r t_{t}$ is $\log$ art price, $D U_{t}$ and $D T_{t}$ are the same as those in Equation (6). For details about how to estimate Equation (6), interested readers can refer to Bahmani-Oskoee et al., (2015).

To analyze persistence, we can not only focus at the conditional mean, but also in the tails of the conditional distribution of $y_{t}$ and here we can estimate Equation (2), using quantile autoregression methods. The $\tau-t h$ conditional quantile is defined as the value $Q_{\tau}\left(y_{t} \mid y_{t-1}, \ldots, y_{t-q}\right)$ such that the probability that art price conditional on its recent and past history will be less than $Q_{\tau}\left(y_{t} \mid y_{t-1}, \ldots, y_{t-q}\right)$ is $\tau$. For example, if art price is very high (low) relative to recent art price this means that a large positive (negative) shock has occurred and that $y_{t}$ is located above (below) the mean conditional on past observations $y_{t-1}, \ldots, y_{t-q}$ somewhere in the upper (lower) conditional quantiles.

The $\operatorname{AR}(\mathrm{q})$ process of art price at quantile $\tau$ can be written as:

$$
Q_{\tau}\left(y_{t} \mid y_{t-1}, \ldots, y_{t-q}\right)=\alpha_{1}(\tau) y_{t-1}+a(\tau)+\sum_{i=1}^{q-1} \phi_{i}(\tau) \Delta y_{t-i} .
$$


By estimating Equation (8) at different quantiles $\tau \in(0,1)$ we can get a set of estimates of the persistence measure as $\alpha_{1}(\tau)$. We can test $\alpha_{1}(\tau)=1$ at different values of $\tau$ to analyze the persistence of art price impact of positive and negative shocks and shocks of different magnitude using the Quantile- based unit root test proposed by Koenker and Xiao (2004).

Let $\alpha_{1}(\tau)$ be the quantile regression estimator. To test $H_{0}: \alpha(\tau)=1$ we use the t-stat for $\alpha_{1}(\tau)$ proposed by Koenker and Xiao (2004) which can be written as

$$
t_{n}(\tau)=\frac{f\left(F^{-1}(\tau)\right)}{\sqrt{\tau(1-\tau)}}\left(y_{-1}^{\prime} M_{Z} y_{-1}\right)^{1 / 2}(\alpha(\tau)-1)
$$

where $f(u)$ and $F(u)$ are the probability and cumulative density functions of $\varepsilon_{t}, y_{-1}$ is the vector of lagged $\log$ art price and $M_{z}$ is the projection matrix onto the space orthogonal to $Z=\left(1, \Delta y_{t-1}, \Delta y_{t-2}, \ldots, \Delta y_{t-q+1}\right)$. We use the results derived by Koenker and Xiao (2004) and Galvao (2009) to find the critical values of $t_{n}(\tau)$ for different quantile levels. We can estimate $f\left(F^{-1}(\tau)\right)$ following the rule given in Koenker and Xiao (2004). Besides allowing for asymmetric effects of shocks on art price, an important advantage of Quantile-based unit root tests over standard unit root tests is that they have more power (Koenker and Xiao, 2004).

In contrast, a more complete inference of the unit root process based on the quantile approach involves exploring the unit root property across a range of quantiles. To this end, Koenker and Xiao (2004) suggest the Quantile Kolmogorov-Smirnov (QKS) test, which is given as

$$
Q K S=\sup _{\tau \in \Gamma}\left|t_{n}(\tau)\right|
$$

where $t_{n}(\tau)$ is given by Equation (9) and $\Gamma=(0.1,0.2, \ldots . .0 .9)^{\prime}$ in our later applications. In other words, we first calculate $t_{n}(\tau)$ for all $\tau_{s}$ in $\Gamma$, and then construct the $Q K S$ test statistic by selecting the maximum value across $\Gamma$. While the limiting distributions of both $t_{n}(\tau)$ and $Q K S$ tests are nonstandard, Koenker and Xiao (2004) suggest the use of a resampling (Number of bootstrap 
$=10000$ in our case) procedure to approximate their small-sample distributions. Interested readers can refer to Koenker and Xiao (2004) for more detailed description.

The goal of all the methods employed in testing for a weak form efficiency in any market is to establish the existence or otherwise of a random behaviour or return independence. If the art index price is mean-reverting, its return is predictable ex ante in the form of a systematic pattern in its dependence on past prices and hence the market is not weak-form efficient. On the other hand, if the art index price follows a random work or martingale, the return is unpredictable from past price information and hence the market is efficient (Lo and MacKinlay, 1988; Charles and Darné, 2009). Unit root tests are valid tools for testing random walk behaviour and hence market efficiency (Lean and Smyth, 2007). This justifies our choice of methodology.

\section{Empirical Results}

To test the efficiency of the art market, we start with the conventional linear unit root and/or stationarity tests namely the Augmented Dickey and Fuller (1979, ADF), Phillips and Perron (1988, PP) and Kwiatkowski et al. (1992, KPSS) tests. The tests are applied to the adjusted series that account for sharp shifts and smooth breaks as shown in Equation (7). The result is presented in Table 2. Based on the ADF and PP tests, we reject the null hypothesis of unit root at $1 \%$ level of significance. This implies that all the 15 art indices are stationary in levels. Similarly, using the KPSS test, we cannot reject the null hypothesis of stationarity in the levels of the art indices. These findings suggest that the art market is not efficient. However, when we applied the test to the original series as is usually done in previous studies, the result is quite different, with all the series containing unit roots with exception of France, Nineteenth century and Old masters. Generally, the conventional linear unit root tests have low power but this is worsened if structural breaks are ignored where they actually exist. It is then not surprising that many previous studies conclude that the art market is efficient as their conclusions are based on a methodology that failed to account for structural breaks in the data. The results based on the original series are presented in the appendix as Table A1. 
Given that the conventional unit root tests are often conducted on the conditional mean of the data, which assumes linearity, we now turn to the quantile-based approach which permits us to test for unit root not only on the conditional mean but at all tails of the distribution of the art indices. We also implemented the quantile unit root for the case of with and without sharp shifts and smooth breaks. The results from a specification that account for the sharp shifts and smooth breaks are presented in Table 3 while the counterpart without breaks is presented as Table A2 in the Appendix. The estimates of autoregressive coefficient (i.e., the persistent parameter $\left(\alpha_{1}(\tau)\right)$, and their corresponding unit root test statistic $\left(t_{n}(\tau)\right)$ are presented for $10^{\text {th }}$ up to $90^{\text {th }}$ quantile alongside with the QKS test. Focusing first on the QKS test, which provides a general perspective of the mean-reverting behaviour of each of the art index by taking the maximum $t_{n}(\tau)$ out of all estimated values at all quantiles, we observe an overwhelming evidence in support of mean-reversion.

Looking at each specific quantile for more detailed examination of the behaviour of the art indices, we immediately observe that the autoregressive coefficients vary across quantiles and are in general not close to unity and therefore are far from being persistent. The only exception where the coefficients are close to or slightly greater than unity are those of Global index (Euro) at all quantiles and Postwar at the upper quantiles. A more formal unit root tests based on $t_{n}(\tau)$ confirms that the null of unit root is rejected for basically all art series at all quantiles, with exception of about 7 series where we observe some form of asymmetric behaviour. For instance, we cannot reject the null of unit root for Global index (USD) at the $80 \%$ and $90 \%$ quantiles. Similarly, we cannot reject the null of unit root at the upper quantile (basically at the $90 \%$ quantile) for Paintings, Prints, Sculptures, Modern art and Postwar. For Global index (Euro), we also cannot reject the null at the lower quantiles, that is, at the $10^{\text {th }}$ and $20^{\text {th }}$ quantiles, with persistent parameters of (-1.324) and (-0.908), respectively. For the rest of the series, we can say that their dynamic behaviour are rather symmetric since the null of unit root is rejected across all quantiles. Overall, given mean reverting behaviour, a shock to the observed art indices is less 
likely to persist for a long period. In other words, shocks to them are short lived and future prices can easily be predicted using the most recent lagged prices. Hence, the art market is in general inefficient. This finding corroborates the argument by David et al. (2013) that it is structurally impossible for auction prices to be efficient since sellers set a minimum transaction price on the artworks for which they have a monopoly and hammer prices are determined solely by bidding, so that there is no upper limit. Consequently, relying on realized prices is insufficient to build unbiased predictions of future prices.

A look at the quantile-based unit root test without breaks as presented in Table A2 shows that based on the QKS tests, the unit root hypothesis is rejected for only three art indices namely France, Prints and UK. When we focus on the autoregressive coefficients and the associated t-statistics, first we observe that coefficients are quite persistent with values very close to unity or slightly above unity and the formal unit root test based on the $t_{n}(\tau)$ supports the persistence behaviour of these series. Overall, based on the quantile tests without breaks, one will be tempted to conclude that the art market is efficient and this is robust across all quantiles. As stated previously omitting structural breaks where one exists tend to overestimate the persistence parameters and lead to under rejection of the null of unit root when the series are actually stationary. This is precisely what we have observed in our analysis. Taking Contemporary as an example, the values of $\alpha_{1}(\tau)$ are increased from $0.057,0.240$ and 0.418 to $0.962,0.988$ and 0.991 for $10 \%, 80 \%$ and $90 \%$ quantiles respectively. This implies that accounting for structural breaks have important effect on the persistence of a series, specifically there is persistence reduction and this has implication on the analysis of market efficiency.

Recall that we have used the Fourier approximation to 'mimic' the time-varying parameter and hence nonlinearity in the art indices. In Table 4, we present the optimum breaks and frequency from the mean reverting function in equation (6) alongside with the estimated Fstatistic that enables us to test for the absence of the nonlinear component in equation (6). In other words the F-statistic is computed by comparing the sum of squared residual (SSR) from 
equation (6) with the nonlinear component (unrestricted model) with the SSR from equation (6) without the nonlinear component (restricted model). However, the critical values for the F-test is non-standard due to nuisance parameters (Becker et al. 2004), hence we follow BahmaniOskooee et al. (2014) and use Monte Carlo simulation to compute the critical values based on 10000 replications. We fixed $\mathrm{k}$ at a maximum of 7 and $\mathrm{m}$ at a maximum of 5 . Results from panel A of Table 4 show that there are a minimum of 3 breaks in each of the art series. For instance, Contemporary has four break points: 2001:3, 2003:1, 2007:1 and 2008:3; Drawings has 3 break points occurring at 1999:1, 2004:4 and 2009:4 while US has 5 break points: 1999:2, 2001:1, 2005:1, 2009:1 and 2008:4. It is interesting to note that even the art market was affected by the recent 2007-2008 financial crisis as we observe breaks in most of the series during these periods. Turning to panel B of Table 4, we observe that the optimum frequency vary from one art index to the other with a minimum of 1 and maximum of 5 optimal frequencies. The computed Fstatistics are in all cases greater than the critical values at least at the $5 \%$ level. Hence, the mean reverting function with the nonlinear component is accepted in favour of the one without the nonlinear component.

Further we present the time paths of the art indices in Figure 1. We present the actual time paths. The Figure shows that there are structural shifts in the art series and hence points to the need to allow for both sharp shifts and smooth breaks in testing for a unit root and/or stationarity. We superimpose the predicted time paths from our model on the actual time paths and we observe that the predicted (that is series ending with suffix, _H) tracks the dynamic behaviour of the art series well, suggesting that the decision to include the dummy variables and Fourier approximations is quite reasonable since the data generating process are indeed nonlinear. 
Table 2: Conventional linear unit root tests on the adjusted art indices

\begin{tabular}{|c|c|c|c|}
\hline Art index & $\mathrm{ADF}$ & $\mathrm{PP}$ & KPSS \\
\hline Contemporary & $-6.876^{* * *}$ & $-9.099 * * *$ & 0.128 \\
\hline Drawings & $-6.333^{* * *}$ & $-7.209 * * *$ & 0.086 \\
\hline France & $-7.800 * * *$ & $-10.628^{* * *}$ & 0.146 \\
\hline Global index (Euro) & $-7.751 * * *$ & $-25.616^{* * *}$ & 0.251 \\
\hline Global index (USD) & $-5.873 * * *$ & $-8.379 * * *$ & 0.067 \\
\hline Modern art & $-5.282 * * *$ & $-4.983^{* * *}$ & 0.088 \\
\hline Nineteenth century & $-6.096 * * *$ & $-5.849 * * *$ & 0.043 \\
\hline Old Masters & $-7.598^{* * *}$ & $-6.687 * * *$ & 0.139 \\
\hline Paintings & $-6.317 * * *$ & $-8.458^{* * *}$ & 0.197 \\
\hline Photographies & $-8.238^{* * *}$ & $-10.254 * * *$ & 0.176 \\
\hline Postwar & $-4.726 * * *$ & $-4.762^{* * *}$ & 0.087 \\
\hline Prints & $-6.086 * * *$ & $-5.996 * * *$ & 0.053 \\
\hline Sculptures & $-5.988 * * *$ & $-4.770 * * *$ & 0.058 \\
\hline UK & $-6.629 * * *$ & $-6.629 * * *$ & 0.125 \\
\hline US & $-6.034 * * *$ & $-6.053 * * *$ & 0.064 \\
\hline
\end{tabular}

***, ${ }^{* *}$ and $*$ indicate rejection of the null hypothesis at $1 \%, 5 \%$ and $10 \%$ level, respectively. 
Table 3: Results of quantile estimation and unit-root tests with sharp shift and smooth breaks

\begin{tabular}{|c|c|c|c|c|c|c|c|c|c|c|}
\hline Art index & $\tau$ & 0.1 & 0.2 & 0.3 & 0.4 & 0.5 & 0.6 & 0.7 & 0.8 & 0.9 \\
\hline \multirow[t]{3}{*}{ Contemporary } & $\alpha_{1}(\tau)$ & $0.543 * * *$ & $-0.021 * * *$ & $0.048^{* * *}$ & $0.044 * * *$ & $0.050 * * *$ & $-0.013 * * *$ & $0.057 * * *$ & $0.240^{* *}$ & $0.418^{*}$ \\
\hline & $\mathrm{t}_{\mathrm{n}}(\tau)$ & -4.377 & -4.331 & -3.945 & -5.185 & -5.121 & -5.185 & -4.996 & -2.957 & -2.21 \\
\hline & QKS & $5.185^{* * *}$ & & & & & & & & \\
\hline \multirow[t]{3}{*}{ Drawings } & $\alpha_{1}(\tau)$ & $0.173^{*}$ & $0.269^{* * *}$ & $0.250 * * *$ & $0.309^{* * *}$ & $0.362^{* * *}$ & $0.373 * * *$ & $0.280^{* * *}$ & $0.302^{* * *}$ & $0.302^{* *}$ \\
\hline & $t_{n}(\tau)$ & -1.812 & -3.051 & -5.816 & -4.982 & -4.816 & -4.58 & -4.823 & -3.936 & -2.974 \\
\hline & QKS & $5.816^{* *}$ & & & & & & & & \\
\hline \multirow[t]{3}{*}{ France } & $\alpha_{1}(\tau)$ & $0.058^{* * *}$ & $0.003^{* * *}$ & $0.018^{* * *}$ & $0.073^{* * *}$ & $0.164 * * *$ & $0.185^{* * *}$ & $0.006^{* * *}$ & $0.003^{* * *}$ & $-0.265^{* * *}$ \\
\hline & $t_{n}(\tau)$ & -3.963 & -5.217 & -6.676 & -5.891 & -5.379 & -4.224 & -3.853 & -3.474 & -4.126 \\
\hline & QKS & $5.891 * * *$ & & & & & & & & \\
\hline \multirow[t]{3}{*}{ Global index (Euro) } & $\alpha_{1}(\tau)$ & -1.324 & -0.908 & $-0.785^{* *}$ & $-0.942^{* * *}$ & $-0.927 * * *$ & $-1.173^{* * *}$ & $-1.056 * * *$ & $-1.231 * *$ & $-1.691 * * *$ \\
\hline & $t_{n}(\tau)$ & -2.834 & -2.004 & -2.668 & -2.994 & -3.845 & -3.856 & -2.972 & -3.269 & -4.584 \\
\hline & QKS & $4.584 * * *$ & & & & & & & & \\
\hline \multirow[t]{3}{*}{ Global index (USD) } & $\alpha_{1}(\tau)$ & $0.415^{* *}$ & $-0.257 * *$ & $-0.270 * *$ & $-0.257 * *$ & $-0.170 * *$ & $-0.330 * *$ & $-0.113^{* *}$ & 0.257 & 0.223 \\
\hline & $t_{n}(\tau)$ & -4.405 & -4.427 & -4.004 & -4.024 & -4.126 & -3.827 & -3.495 & -1.526 & -2.043 \\
\hline & QKS & $4.405^{* * *}$ & & & & & & & & \\
\hline \multirow[t]{3}{*}{ Modern art } & $\alpha_{1}(\tau)$ & $-0.006^{* * *}$ & $0.393^{* * *}$ & $0.425^{* * *}$ & $0.460 * * *$ & $0.521 * * *$ & $0.523^{* * *}$ & $0.579 * * *$ & $0.499 * * *$ & 0.474 \\
\hline & $t_{n}(\tau)$ & -3.835 & -3.641 & -3.55 & -3.594 & -3.37 & -3.058 & -2.487 & -2.858 & -2.872 \\
\hline & QKS & $3.835^{* * *}$ & & & & & & & & \\
\hline \multirow[t]{3}{*}{ Nineteenth century } & $\alpha_{1}(\tau)$ & $-0.240 * * *$ & $-0.069 * * *$ & $0.172 * * *$ & $0.153^{* * *}$ & $0.217 * * *$ & $0.162^{* * *}$ & $0.110^{* *}$ & $0.287 * *$ & $0.242^{*}$ \\
\hline & $t_{n}(\tau)$ & -4.816 & -3.725 & -3.426 & -3.691 & -3.923 & -4.876 & -5.186 & -3.058 & -1.999 \\
\hline & QKS & $5.816^{* * *}$ & & & & & & & & \\
\hline \multirow[t]{3}{*}{ Old masters } & $\alpha_{1}(\tau)$ & $0.332 * * *$ & $-0.120 * * *$ & $-0.129 * * *$ & $-0.027 * * *$ & $-0.203^{* * *}$ & $-0.104 * * *$ & $0.025^{* * *}$ & $0.016^{* * *}$ & $0.364 *$ \\
\hline & $\mathrm{t}_{\mathrm{n}}(\tau)$ & -4.243 & -5.331 & -5.369 & -5.89 & -6.834 & -5.171 & -5.269 & -4.098 & -1.762 \\
\hline & QKS & $6.834 * * *$ & & & & & & & & \\
\hline \multirow[t]{3}{*}{ Paintings } & $\alpha_{1}(\tau)$ & $-0.344 * * *$ & $-0.251 * * *$ & $0.056^{* * *}$ & $0.240 * * *$ & $0.334 * * *$ & $0.235^{* * *}$ & $0.255^{* * *}$ & $0.210^{* * *}$ & 0.855 \\
\hline & $\mathrm{t}_{\mathrm{n}}(\tau)$ & -6.088 & -4.959 & -3.912 & -3.332 & -3.153 & -3.887 & -3.157 & -2.792 & -0.505 \\
\hline & QKS & $6.088^{* * *}$ & & & & & & & & \\
\hline
\end{tabular}




\begin{tabular}{|c|c|c|c|c|c|c|c|c|c|c|}
\hline Art index & $\tau$ & 0.1 & 0.2 & 0.3 & 0.4 & 0.5 & 0.6 & 0.7 & 0.8 & 0.9 \\
\hline \multirow[t]{3}{*}{ Photographies } & $\alpha_{1}(\tau)$ & $0.089 * * *$ & $-0.130 * * *$ & $-0.190^{* * *}$ & $-0.152^{* * *}$ & $-0.034 * * *$ & $-0.091 * * *$ & $-0.263^{* * *}$ & $-0.159 * * *$ & $-0.319 * * *$ \\
\hline & $t_{n}(\tau)$ & -4.259 & -6.576 & -6.824 & -6.966 & -5.775 & -5.725 & -5.675 & -4.253 & -3.523 \\
\hline & QKS & $6.966^{* * *}$ & & & & & & & & \\
\hline \multirow[t]{3}{*}{ Postwar } & $\alpha_{1}(\tau)$ & $0.103^{* * *}$ & $0.265^{* * *}$ & $0.403^{* *}$ & $0.613^{* *}$ & $0.625^{*}$ & $0.722^{*}$ & 0.759 & 0.866 & 0.828 \\
\hline & $t_{n}(\tau)$ & -3.726 & -3.117 & -2.539 & -2.517 & -2.587 & -1.899 & -1.894 & -1.011 & -1.128 \\
\hline & QKS & $3.726^{* * *}$ & & & & & & & & \\
\hline \multirow[t]{3}{*}{ Prints } & $\alpha_{1}(\tau)$ & $0.215^{* * *}$ & $0.300^{* * *}$ & $0.509^{* * *}$ & $0.485^{* * *}$ & $0.565^{* * *}$ & $0.563^{* * *}$ & $0.448^{* * *}$ & $0.490 * * *$ & 0.459 \\
\hline & $t_{n}(\tau)$ & -3.351 & -3.057 & -3.229 & -2.912 & -3.779 & -3.503 & -4.065 & -2.902 & -1.643 \\
\hline & QKS & $4.065^{* * *}$ & & & & & & & & \\
\hline \multirow[t]{3}{*}{ Sculptures } & $\alpha_{1}(\tau)$ & $-0.260^{* * *}$ & $-0.281 * * *$ & $-0.033^{* * *}$ & $0.094 * * *$ & $0.144 * * *$ & $0.095^{* * *}$ & $0.033^{* * *}$ & $0.280^{* * *}$ & 0.551 \\
\hline & $t_{n}(\tau)$ & -4.757 & -4.839 & -4.11 & -3.845 & -3.958 & -4.105 & -5.071 & -3.124 & -1.951 \\
\hline & QKS & 5.071 *** & & & & & & & & \\
\hline \multirow[t]{3}{*}{ UK } & $\alpha_{1}(\tau)$ & $-0.076^{* * *}$ & $0.086^{* * *}$ & $0.210^{* * *}$ & $0.365^{* * *}$ & $0.455^{* * *}$ & $0.538^{* * *}$ & $0.520^{* * *}$ & $0.384 * * *$ & $0.335^{* * *}$ \\
\hline & $t_{n}(\tau)$ & -4.579 & -5.458 & -5.99 & -4.476 & -3.216 & -2.641 & -2.408 & -3.183 & -3.043 \\
\hline & QKS & $5.990^{* * *}$ & & & & & & & & \\
\hline \multirow[t]{3}{*}{ US } & $\alpha_{1}(\tau)$ & $0.410^{*}$ & $0.373^{* *}$ & $0.443^{* * *}$ & $0.316^{* * *}$ & $0.302^{* * *}$ & $0.325^{* * *}$ & $0.456^{* * *}$ & $0.413^{* * *}$ & $0.363^{* * *}$ \\
\hline & $\mathrm{t}_{\mathrm{n}}(\tau)$ & -1.851 & -2.42 & -3.506 & -6.209 & -4.299 & -4.484 & -3.676 & -3.267 & -3.095 \\
\hline & QKS & $6.209 * * *$ & & & & & & & & \\
\hline
\end{tabular}

Notes: ${ }^{* *},{ }^{* *}$ and $*$ denote significance at $1 \%, 5 \%$ and $10 \%$ level, respectively. Lag length was chosen by the BIC with the maximum lag set to be 12 . For $\alpha_{1}(\tau)$, the unitroot null is examined with the $\mathrm{t}_{\mathrm{n}}(\tau)$ statistic. 
Table 4: Break Dates and Optimum Frequency from the Mean Reverting Function

\begin{tabular}{lrrrrrr}
\hline Panel A: Sharp drift dates from 1998:1 & & & & \\
\hline Contemporary & 2001.3 & 2003.1 & 2007.1 & 2008.3 & 0 & 4 \\
Drawings & 1999.1 & 2004.4 & 2009.4 & 0 & 0 & 3 \\
France & 1999.4 & 2002.1 & 2007.2 & 2008.4 & 2014.2 & 5 \\
Global index (Euro) & 1999.3 & 2004.1 & 2008.3 & 2009.4 & 0 & 4 \\
Global index (USD) & 2003.4 & 2006.1 & 2010.4 & 0 & 0 & 3 \\
Modern art & 2000.4 & 2002.1 & 2006.1 & 2012.1 & 2010.4 & 5 \\
Nineteenth century & 1999.2 & 2007.2 & 2008.4 & 2010.4 & 0 & 4 \\
Old Masters & 2000.4 & 2002.1 & 2009.1 & 2012.1 & 0 & 4 \\
Paintings & 2002.1 & 2003.4 & 2007.1 & 2007.4 & 2010.4 & 5 \\
Photographies & 1999.4 & 2001.3 & 2003.3 & 2005.1 & 2008.4 & 5 \\
Postwar & 2000.3 & 2006.1 & 2009.4 & 2010.3 & 0 & 4 \\
Prints & 2003.1 & 2006.2 & 2008.3 & 2010.1 & 2013.1 & 5 \\
Sculptures & 2003.1 & 2005.1 & 2006.1 & 2008.4 & 2011.1 & 5 \\
UK & 1999.3 & 2004.4 & 2006.1 & 2007.4 & 2010.1 & 5 \\
US & 1999.2 & 2001.1 & 2005.1 & 2009.1 & 2008.4 & 5 \\
\hline
\end{tabular}

\begin{tabular}{lrrrrrr}
\multicolumn{6}{l}{ Panel B: The results for optimum frequency and the F-statistic and its critical values } \\
\hline \multirow{2}{*}{ Art index } & $\begin{array}{l}\text { Optimum } \\
\text { frequency }\end{array}$ & \multicolumn{1}{c}{ F-Stat } & 0.900 & 0.950 & 0.975 & 0.990 \\
\hline Contemporary & 3.000 & 7.632 & 2.399 & 3.120 & 3.843 & 5.054 \\
Drawings & 5.000 & 12.521 & 2.386 & 3.154 & 3.923 & 5.025 \\
France & 3.000 & 73.906 & 2.477 & 3.291 & 4.127 & 5.067 \\
Global index (Euro) & 5.000 & 3.752 & 2.383 & 3.119 & 3.992 & 5.027 \\
Global index (USD) & 5.000 & 13.232 & 2.405 & 3.160 & 3.984 & 5.075 \\
Modern art & 1.000 & 89.000 & 2.414 & 3.187 & 3.971 & 4.897 \\
Nineteenth century & 3.000 & 12.469 & 2.371 & 3.205 & 4.062 & 5.156 \\
Old Masters & 5.000 & 8.963 & 2.404 & 3.138 & 3.975 & 5.069 \\
Paintings & 4.000 & 6.265 & 2.381 & 3.187 & 3.846 & 4.981 \\
Photographies & 5.000 & 19.751 & 2.394 & 3.155 & 3.891 & 5.073 \\
Postwar & 1.000 & 313.215 & 2.380 & 3.107 & 3.871 & 4.734 \\
Prints & 1.000 & 26.928 & 2.443 & 3.128 & 4.049 & 5.013 \\
Sculptures & 3.000 & 5.977 & 2.398 & 3.179 & 4.094 & 5.223 \\
UK & 5.000 & 3.308 & 2.404 & 3.151 & 3.884 & 4.921 \\
US & 5.000 & 22.207 & 2.412 & 3.152 & 3.886 & 4.898 \\
\hline
\end{tabular}

Note: The maximum number of break was fixed at 5 . We compute the critical values using Monte Carlo simulation based on 10,000 replications. 

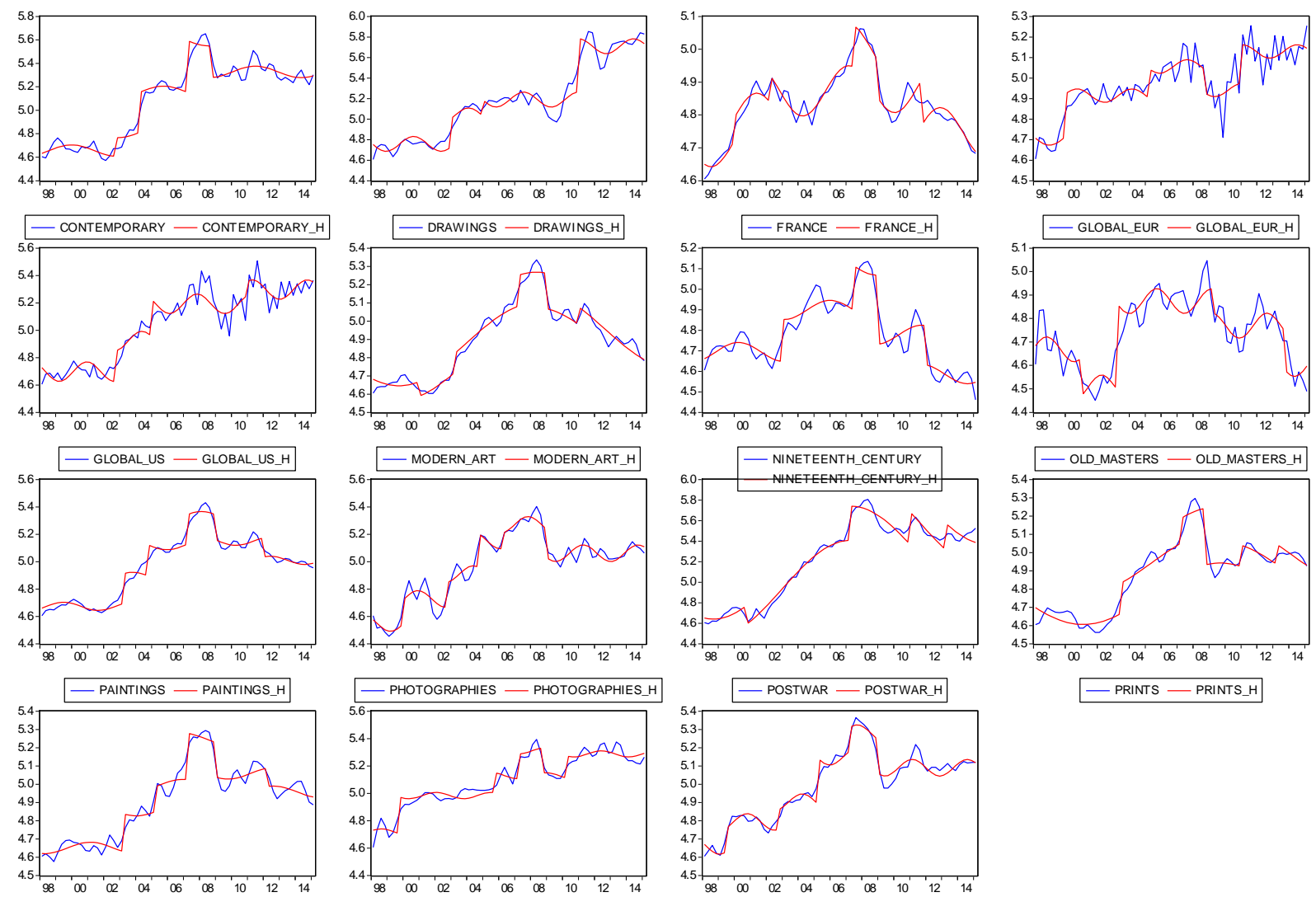

- PRINTS — PRINTS_H

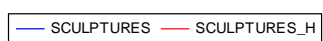

- UK - UK_H

- US - US_H

Figure 1: Plots of log of art indices and fitted nonlinearities

\section{Conclusion}

The question as to the efficiency of a particular market is usually of interest to both investors and practitioners. This study investigated the efficiency of the art market using a novel nonlinear quantile-based unit root test that accounts for both sharp shifts and smooth breaks in the data. We model the nonlinearity in the data using Fourier approximation. Our analysis involve 15 art indices- Contemporary, Drawings, France, Global index (Euro), Global index (USD), Modern art, Nineteenth century, Old Masters, Paintings, Photographies, Postwar, Prints, Sculptures, UK and US- and our data is quarterly one covering 1998: 1 to 2015:1. Prior to implementing the proposed quantile-based test we conducted the conventional unit root test on the original series and our newly constructed series that account for both sharp shifts and smooth breaks. Results based on these are in contrast with each other, with the test applied to 
the original series not able to reject the null of unit root in general while the tests on the transformed series rejected the null of unit root for all the art indices. Our analysis provided evidence of structural breaks and nonlinearity in the data. Using the quantile-based test with sharp shifts and smooth breaks accounted for, we find overwhelming evidence in support of mean reverting behaviour in the art series. However, we note that the two global indices, Paintings, Prints, Sculptures, Modern art and Postwar showed some form of asymmetric behaviour with evidence of unit root at some quantiles while none at other quantiles. A similar test without breaks however indicate the series are in general persistent, that is, have unit root. We also find strong evidence of persistence reductions using the model with breaks. Our findings have some important implications. They point to the importance of allowing for sharp shifts and smooth breaks as well as nonlinearity in modelling the art market as failure to do so might have led to the conclusions in the previous studies that the art market prices are unit root processes. Our result also show that relying on a single measure of conditional central tendency as done in the previous art studies could lead to erroneous conclusion that any evidence found is constant or uniform across all quantiles.

More importantly, the evidence of mean reverting behaviour in all the art series suggest that shocks to the markets are short lived and art returns can be predicted, hence the market is not efficient. Since art prices do not fully reflect all available information in the market, market participants can incorporate any hidden information into their investment and/or management strategies and consequently make excessive gains from participating in the market. In this market, players can easily time their security sales; for instance buying undervalued assets and selling them in the future when the prices increase. The finding also implies that firms do not receive a fair value of the securities they sell and investors can as well be fooled by financial managers (agents) regarding the returns from investing in the art market. An inefficient market can stifle competition and hence drive markets to unnecessary competition. While it may be agreed that the role of policy is limited since shocks are temporary and somehow there are forces 
that will bring the market to its equilibrium in the long run. However, policies that improve participants' access to market information and perhaps credit may act as incentives especially for small firms to invest in such market. This is because asymmetry in information is the basic source of inefficiency-mispricing, bubbles, crashes- thus transparency in trade can help to reduce the observed inefficiency in the art market. Capping annual turnover and subsequent withdrawal of tax exemption or subsidies from firms that fail to cap turnover may also help. 


\section{References}

Artprice (2013). The art market in 2013. Available at http://imgpublic.artprice.com/pdf/trends2013_en_fr_de_es_online.pdf.

Ashenfelter, O. and Graddy, K. (2003). Auctions and the price of art. Journal of Economic Literature, 41(3), 763-787.

Atukeren, E. and Seçkin, A. (2009). An analysis of the price dynamics between the Turkish and the international paintings markets. Applied Financial Economics, 19, 1705-1714.

Aye, G.C., Gil-Alana, L.A., Gupta, R. and Wohar, M. (2016) The efficiency of the art market: Evidence from variance ratio tests, Linear and Nonlinear Fractional Integration Approaches. Department of Economics Working Paper Series, University of Pretoria, 2016-10.

Bahmani-Oskooee, M., Chang, T., and Wu, T-P. (2014) Revisiting purchasing power parity in African countries: panel stationary test with sharp and smooth breaks, Applied Financial Economics, 24, 22, 1429-1438.

Bahmani-Oskoee, Mohsen., Chang, T and Wu, T-P (2015) Purchasing Power Parity in Transition Countries: Panel Stationary Test with Smooth and Sharp Breaks, International Journal of Financial Studies, May, 3, 153-161.

Baumol, W. (1986). Unnatural value: Or art as floating crap game. American Economic Review $76,10-14$.

Becker, R., Enders, W., and Lee, J. (2004), A general test for time dependence in parameters, Journal of Applied Econometrics, 19, 899-906.

Becker, R., Enders, W., and Lee, J. (2006) A stationarity test in the presence of an unknown number of smooth breaks, Journal of Time Series Analysis, 27, 381-409.

Campbell, R. (2008). Art as a financial investment. The Journal of Alternative Investments Spring, 10(4), 64-81.

Carrion-I-Silvestre, J. I., Del Barrio, T. and López-Bazo, E. (2004) Evidence on the purchasing power parity in a panel of cities, Applied Economics, 36, 961-6. 
Çevik, E.I., Atukeren, E. and Korkmaz, T. (2013) Nonlinearity and nonstationarity in international art market prices: evidence from Markov-switching ADF unit root tests. Empirical Economics, 45(2), 675-695.

Chanel, O. (1995) Is art market behaviour predictable. Eur Econ Rev 39:519-527.

Charles, A. and Darné, O. (2009). The efficiency of the crude oil markets: Evidence from variance ratio tests, Energy Policy, 37, 4267-4272.

Chen, W-Y., Chang, T-Y and Lin, Y-H. (2015) Investigating the Persistence of Suicide in the United States: Evidence from the Quantile Unit Root Test, Empirical Economics, (under review).

Cochrane, J.H. (2013) Eugene F. Fama, efficient markets, and the Nobel Prize. http://www.chicagobooth.edu/capideas/magazine/winter-2013/eugene-fama-efficientmarkets-and-the-nobel-prize.

David, G., Oosterlinck, K. and Szafarz, A. (2013). Art market inefficiency, Economics Letters $121,23-25$.

Dickey, D. A., and Fuller, W. A. (1979). Distribution of the estimators for autoregressive time series with a unit root. Journal of the American statistical association, 74(366a), 427-431.

Enders, W. and Holt, M. T. (2012) Sharp breaks or smooth shifts? An investigation of the evolution of primary commodity prices, American Journal of Agricultural Economics, 94, 659-73. doi:10.1093/ajae/aar162.

Enders, W., and Lee, J. (2012) A unit root test using a Fourier series to approximate smooth breaks, Oxford Bulletin of Economics and Statistics, 74(4), 574-599.

Erdös, P. and Ormos, M. (2010). Random walk theory and the weak-form efficiency of the US art auction prices. Journal of Banking \& Finance 34 (5), 1062-1076. Fama, E.F. (1970). Efficient capita.

Gallant, R., (1981) On the basis in flexible functional form and an essentially unbiased form: The flexible Fourier form, Journal of Econometrics, 15, 211-353. 
Galvao, A. F. (2009) Unit root quantile autoregression testing using covariates. Journal of Econometrics 152, 165-178.

Gibbons, M., and Ross, S. and Shanken, J. (1989). A test of the efficiency of a given portfolio. Econometrica, 57, 1121-1152.

Goetzmann, W. N. (1995). The informational efficiency of the art market. Managerial Finance. 21(6), $25-34$.

Hodgson, D.J. and Vorkink, K.P. (2004) Asset pricing theory and the valuation of Canadian paintings. Can J Econ 37:629-655.

Koenker, R. and Xiao, Z. (2004) Unit root quantile autoregression inference. Journal of the American Statistical Association, 99 (467), 775-787.

Korteweg, A.G., Kräussl, R. and Verwijmeren, P. (2015) Does it pay to invest in art? A SelectionCorrected Returns Perspective, forthcoming in Review of Financial Studies. Available at SSRN: http://ssrn.com/abstract $=2280099$ or http://dx.doi.org/10.2139/ssrn.2280099.

Kräussl, R., Lehnert, T. and Martelin, N. (2016) Is there a bubble in the art market? Journal of Empirical Finance, 35 (2016) 99-109.

Kwiatkowski, D., Phillips, P.C.B., Schmidt P., and Shin Y. (1992) Testing the null hypothesis of stationarity against the alternative of a unit root: How sure are we that economic time series have a unit root? Journal of Econometrics, 54 (1-3), 159-178.

Lo, A. W. and MacKinlay, A. C. (1988). Stock market prices do not follow random walks: Evidence from a simple specification test. Review of Financial Studies, 1(1), 41-66.

Louargand, M.A. and McDaniel, J.R. (1991). Price efficiency in the art auction market, Journal of Cultural Economics, 15(2), 53-65.

Lean, H.H. and Smyth, R. (2007). Do Asian stock markets follow a random walk? Evidence from LM unit root tests with one and two structural breaks. Review of Pacific Basin Financial Markets and Policies. 10, 15-31. 
McAndrew, C. (2008). The Art Economy: An Investor's Guide to the Art Market. Liffey Press, Dublin.

Munteanu, A., and Pece, A., (2015) Investigating art market efficiency, Procedia - Social and Behavioral Sciences 188. 82-88.

Perron, P. (1989) The great crash, the oil price shock, and the unit root hypothesis, Econometrica, $55,277-302$

Phillips, P. C. B. and P. Perron (1988) Testing for a unit root in time series regression, 22 Biometrica, 75, 335-346.

Picinati di Torcello, A. and Petterson, A. (2014) Art \& Finance report's 2014 edition.

http://www.abbl.lu/en/blog/article/2014/09/wealth-management-industry-is-taking-amore-strategic-view-on-art-as-an-asset-class.

Renneboog, L. and Spaenjers, C. (2013). Buying beauty: on prices and returns in the art market. Management Science, 59 (1), 36-53.

Stein, J. (1977) The monetary appreciation of paintings. Journal of Political Economy, 85(5), 1021-1035.

Tsong, C.C., and Lee, C.F. (2011) Asymmetric inflation dynamics evidence from quantile regression analysis. Journal of Macroeconomics, 33, 668-680.

Worthington, A.C., and Higgs, H. (2003) Art as an investment: short and long-term comovements in major painting markets. Empir Econ 28:649-668. 


\section{Appendix}

Table A1: Conventional linear unit root tests on original art series

\begin{tabular}{|c|c|c|c|c|c|c|}
\hline & Level & & & First differe & & \\
\hline Art index & $\mathrm{ADF}$ & PP & KPSS & $\mathrm{ADF}$ & PP & KPSS \\
\hline Contemporary & -1.400 & -1.456 & $0.855^{* * *}$ & $-3.653 * * *$ & $-4.520 * * *$ & 0.138 \\
\hline Drawings & -0.099 & -0.748 & $0.986^{* * *}$ & $-3.995 * * *$ & $-4.416 * * *$ & 0.043 \\
\hline France & -1.906 & -2.197 & 0.237 & $-2.756^{*}$ & $-4.814^{* * *}$ & $0.377^{*}$ \\
\hline Global index (Euro) & -2.382 & $-3.311 * *$ & $0.861^{* * *}$ & $-3.506^{* *}$ & $-17.539 * * *$ & 0.178 \\
\hline Global index (USD) & -1.271 & -1.571 & $0.965^{* * *}$ & $-6.345^{* * *}$ & $-15.793^{* * *}$ & 0.159 \\
\hline Modern art & -1.694 & -1.500 & $0.564 * * *$ & $-3.546^{* * *}$ & $-3.955^{* * *}$ & $0.380^{*}$ \\
\hline Nineteenth century & -0.606 & -0.832 & 0.254 & $-3.616 * * *$ & $-2.980 * *$ & 0.297 \\
\hline Old Masters & -1.735 & -1.806 & 0.248 & $-3.139 * *$ & $-7.901 * * *$ & 0.219 \\
\hline Paintings & -1.561 & -1.640 & $0.673^{* *}$ & $-3.745^{* * *}$ & $-3.343^{* *}$ & 0.315 \\
\hline Photographies & -2.072 & -1.667 & $0.689 * *$ & $-5.074 * * *$ & $-4.833^{* * *}$ & 0.166 \\
\hline Postwar & -1.420 & -1.445 & $0.874 * *$ & -2.268 & $-4.668 * * *$ & 0.232 \\
\hline Prints & -1.484 & -1.663 & $0.710^{* *}$ & $-4.335^{* * *}$ & $-2.900 * *$ & 0.134 \\
\hline Sculptures & -1.412 & -1.628 & $0.736 * *$ & $-3.177 * *$ & $-4.249 * * *$ & 0.228 \\
\hline UK & -2.486 & $-2.757^{*}$ & $0.981 * * *$ & $-4.513 * * *$ & $-8.660 * * *$ & 0.306 \\
\hline US & -2.080 & -1.974 & $0.784 * * *$ & $-4.045^{* * *}$ & $-3.815^{* * *}$ & 0.169 \\
\hline
\end{tabular}

Note: $* * *, * *$ and $*$ indicate rejection of the null hypothesis at $1 \%, 5 \%$ and $10 \%$ level, respectively. 
Table A2: Results of quantile estimation and unit-root tests without breaks

\begin{tabular}{|c|c|c|c|c|c|c|c|c|c|c|}
\hline Art index & $\tau$ & 0.1 & 0.2 & 0.3 & 0.4 & 0.5 & 0.6 & 0.7 & 0.8 & 0.9 \\
\hline \multirow[t]{4}{*}{ Contemporary } & $\alpha_{1}(\tau)$ & 0.964 & 0.994 & 0.955 & 0.954 & 0.951 & 0.955 & 0.962 & 0.988 & 0.991 \\
\hline & $t_{n}(\tau)$ & -0.834 & -0.177 & -1.627 & -1.802 & -2.147 & -1.719 & -1.360 & -0.446 & -0.314 \\
\hline & $\mathrm{CV}$ & -2.322 & -2.606 & -2.664 & -2.745 & -2.685 & -2.571 & -2.551 & -2.460 & -2.390 \\
\hline & QKS & $2.147(2.784)$ & & & & & & & & \\
\hline \multirow[t]{4}{*}{ Drawings } & $\alpha_{1}(\tau)$ & 0.969 & 0.980 & 0.982 & 0.987 & 1.014 & 1.011 & 1.015 & 0.989 & 1.024 \\
\hline & $t_{n}(\tau)$ & -0.954 & -0.695 & -0.783 & -0.590 & 0.599 & 0.470 & 0.504 & -0.258 & 0.607 \\
\hline & $\mathrm{CV}$ & -2.541 & -2.485 & -2.350 & -2.409 & -2.480 & -2.358 & -2.565 & -2.429 & -2.670 \\
\hline & QKS & $0.954(2.805)$ & & & & & & & & \\
\hline \multirow[t]{4}{*}{ France } & $\alpha_{1}(\tau)$ & 0.843 & 0.898 & 0.894 & 0.921 & 0.927 & 0.975 & 1.024 & 1.016 & 0.953 \\
\hline & $t_{n}(\tau)$ & -4.907 & -2.930 & -2.632 & -1.861 & -1.729 & -0.521 & 0.463 & 0.294 & -1.074 \\
\hline & $\mathrm{CV}$ & -2.475 & -2.594 & -2.762 & -2.666 & -2.745 & -2.621 & -2.581 & -2.332 & -2.528 \\
\hline & QKS & $4.907 * *(2.757)$ & & & & & & & & \\
\hline \multirow[t]{4}{*}{ Global index (Euro) } & $\alpha_{1}(\tau)$ & 0.785 & 0.859 & 0.858 & 0.784 & 0.853 & 0.831 & 0.817 & 0.892 & 0.943 \\
\hline & $t_{n}(\tau)$ & -1.479 & -1.113 & -1.537 & -2.514 & -1.792 & -2.172 & -2.131 & -0.900 & -0.373 \\
\hline & CV & -2.473 & -2.625 & -2.495 & -2.708 & -2.565 & -2.597 & -2.378 & -2.531 & -2.636 \\
\hline & QKS & $2.514(2.780)$ & & & & & & & & \\
\hline \multirow[t]{4}{*}{ Global index (USD) } & $\alpha_{1}(\tau)$ & 0.903 & 0.968 & 0.952 & 0.948 & 0.942 & 0.937 & 0.925 & 0.945 & 1.076 \\
\hline & $t_{n}(\tau)$ & -1.923 & -0.515 & -0.859 & -1.032 & -1.321 & -1.038 & -1.094 & -0.706 & 0.835 \\
\hline & CV & -2.183 & -2.486 & -2.627 & -2.664 & -2.603 & -2.452 & -2.579 & -2.334 & -2.313 \\
\hline & QKS & $1.923(2.800)$ & & & & & & & & \\
\hline \multirow[t]{4}{*}{ Modern art } & $\alpha_{1}(\tau)$ & 0.933 & 0.953 & 0.953 & 0.970 & 0.962 & 0.979 & 0.990 & 1.012 & 1.016 \\
\hline & $t_{n}(\tau)$ & -2.692 & -1.576 & -1.941 & -1.478 & -1.666 & -0.978 & -0.396 & 0.371 & 0.661 \\
\hline & $\mathrm{CV}$ & -2.734 & -2.486 & -2.620 & -2.643 & -2.747 & -2.544 & -2.655 & -2.526 & -2.483 \\
\hline & QKS & $2.692(2.789)$ & & & & & & & & \\
\hline \multirow[t]{4}{*}{ Nineteenth century } & $\alpha_{1}(\tau)$ & 0.965 & 0.975 & 0.962 & 1.011 & 0.982 & 0.975 & 0.982 & 0.958 & 0.937 \\
\hline & $t_{n}(\tau)$ & -0.762 & -0.443 & -0.904 & 0.292 & -0.429 & -0.603 & -0.501 & -0.832 & -1.679 \\
\hline & CV & -2.610 & -2.678 & -2.401 & -2.631 & -2.596 & -2.743 & -2.772 & -2.425 & -2.356 \\
\hline & QKS & $1.679(2.769)$ & & & & & & & & \\
\hline \multirow[t]{4}{*}{ Old Masters } & $\alpha_{1}(\tau)$ & 0.865 & 0.874 & 0.874 & 0.910 & 0.906 & 0.890 & 0.944 & 0.959 & 0.940 \\
\hline & $t_{n}(\tau)$ & -1.653 & -1.276 & -1.743 & -1.437 & -1.564 & -1.710 & -0.931 & -0.620 & -0.791 \\
\hline & $\mathrm{CV}$ & -2.528 & -2.536 & -2.544 & -2.806 & -2.838 & -2.671 & -2.715 & -2.602 & -2.621 \\
\hline & QKS & $1.743(2.783)$ & & & & & & & & \\
\hline
\end{tabular}




\begin{tabular}{|c|c|c|c|c|c|c|c|c|c|c|}
\hline Art index & $\tau$ & 0.1 & 0.2 & 0.3 & 0.4 & 0.5 & 0.6 & 0.7 & 0.8 & 0.9 \\
\hline \multirow{4}{*}{ Paintings } & $\alpha_{1}(\tau)$ & 0.973 & 0.974 & 0.949 & 0.964 & 0.974 & 0.986 & 0.997 & 0.997 & 0.988 \\
\hline & $t_{n}(\tau)$ & -1.483 & -1.096 & -2.509 & -1.954 & -1.822 & -0.829 & -0.174 & -0.116 & -0.412 \\
\hline & $\mathrm{CV}$ & -2.337 & -2.646 & -2.621 & -2.742 & -2.759 & -2.662 & -2.478 & -2.566 & -2.484 \\
\hline & QKS & $2.509(2.772)$ & & & & & & & & \\
\hline \multirow[t]{4}{*}{ Photographies } & $\alpha_{1}(\tau)$ & 0.948 & 0.990 & 0.969 & 0.957 & 0.932 & 0.916 & 0.937 & 0.927 & 0.971 \\
\hline & $t_{n}(\tau)$ & -1.876 & -0.272 & -0.836 & -1.271 & -1.961 & -2.318 & -1.772 & -1.665 & -0.771 \\
\hline & $\mathrm{CV}$ & -2.492 & -2.493 & -2.737 & -2.775 & -2.609 & -2.524 & -2.402 & -2.369 & -2.120 \\
\hline & QKS & $2.318(2.795)$ & & & & & & & & \\
\hline \multirow[t]{4}{*}{ Postwar } & $\alpha_{1}(\tau)$ & 0.994 & 0.973 & 0.965 & 0.986 & 0.981 & 0.971 & 0.976 & 0.976 & 0.959 \\
\hline & $t_{n}(\tau)$ & -0.364 & -1.317 & -1.824 & -0.721 & -1.172 & -1.532 & -1.461 & -1.508 & -1.339 \\
\hline & $\mathrm{CV}$ & -2.518 & -2.682 & -2.797 & -2.801 & -2.686 & -2.563 & -2.385 & -2.445 & -2.353 \\
\hline & QKS & $1.824(2.780)$ & & & & & & & & \\
\hline \multirow[t]{4}{*}{ Prints } & $\alpha_{1}(\tau)$ & 0.943 & 0.974 & 0.973 & 0.976 & 0.972 & 0.978 & 0.968 & 0.996 & 1.008 \\
\hline & $t_{n}(\tau)$ & -3.122 & -1.070 & -1.422 & -1.145 & -1.262 & -0.990 & -1.268 & -0.154 & 0.417 \\
\hline & CV & -2.677 & -2.542 & -2.577 & -2.687 & $\mathrm{NaN}$ & -2.750 & -2.704 & -2.322 & -2.379 \\
\hline & QKS & $3.122 * *(2.760)$ & & & & & & & & \\
\hline \multirow[t]{4}{*}{ Sculptures } & $\alpha_{1}(\tau)$ & 0.942 & 0.937 & 0.946 & 0.958 & 0.957 & 0.961 & 0.967 & 0.992 & 0.994 \\
\hline & $t_{n}(\tau)$ & -2.564 & -1.933 & -1.895 & -1.458 & -1.687 & -1.188 & -1.042 & -0.199 & -0.149 \\
\hline & $\mathrm{CV}$ & -2.349 & -2.583 & -2.611 & -2.582 & -2.532 & -2.504 & -2.701 & -2.677 & -2.382 \\
\hline & QKS & $2.564(2.807)$ & & & & & & & & \\
\hline \multirow[t]{4}{*}{ UK } & $\alpha_{1}(\tau)$ & 0.921 & 0.933 & 0.923 & 0.941 & 0.947 & 0.962 & 0.999 & 1.028 & 0.994 \\
\hline & $t_{n}(\tau)$ & -2.913 & -2.087 & -3.001 & -2.167 & -1.977 & -1.430 & -0.018 & 0.693 & -0.172 \\
\hline & $\mathrm{CV}$ & -2.120 & -2.449 & -2.723 & -2.748 & -2.722 & -2.656 & -2.781 & -2.235 & -2.250 \\
\hline & QKS & $3.001 * *(2.761)$ & & & & & & & & \\
\hline \multirow[t]{4}{*}{ US } & $\alpha_{1}(\tau)$ & 0.957 & 0.950 & 0.967 & 0.930 & 0.926 & 0.938 & 0.945 & 0.939 & 0.970 \\
\hline & $t_{n}(\tau)$ & -1.376 & -1.611 & -1.119 & -2.621 & -2.588 & -2.195 & -2.260 & -2.258 & -1.026 \\
\hline & CV & -2.561 & -2.705 & -2.825 & -2.700 & -2.690 & -2.673 & -2.644 & -2.744 & -2.329 \\
\hline & QKS & $2.621(2.774)$ & & & & & & & & \\
\hline
\end{tabular}

$5 \%$ critical values; NaN : No convergence during estimation; Values in parenthesis are CV for $\mathrm{QKS}$. 